\title{
VITAL DECOMPOSITION
}




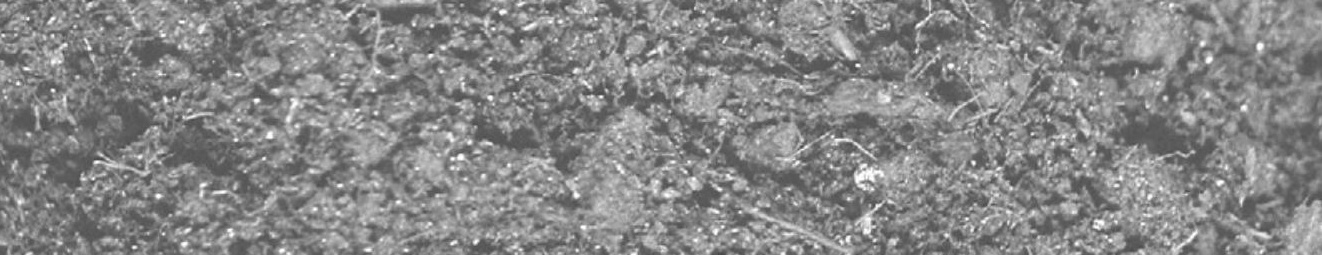

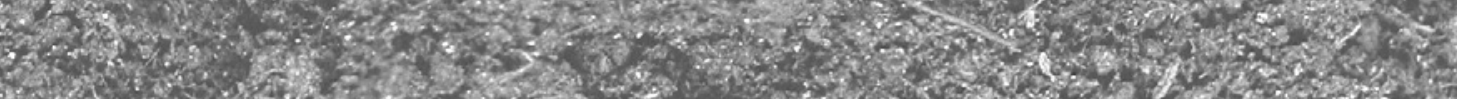

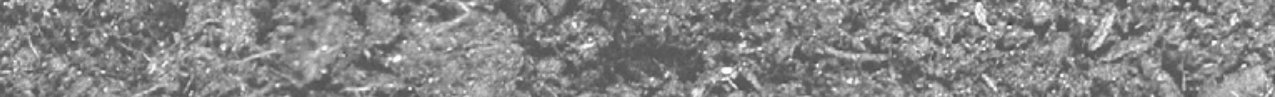
60 $x$ z

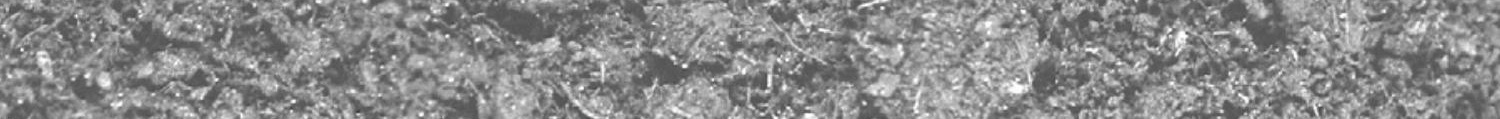

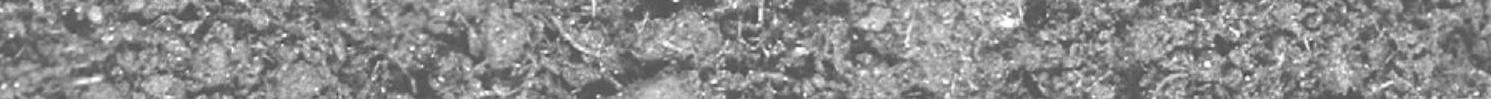

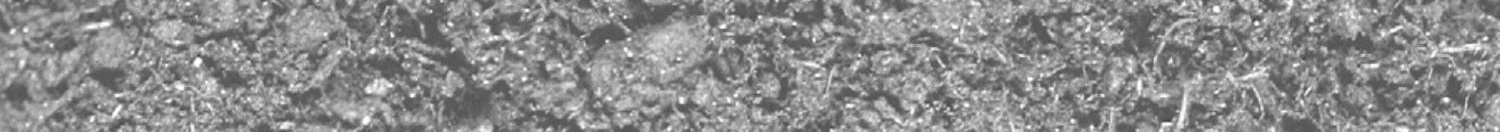

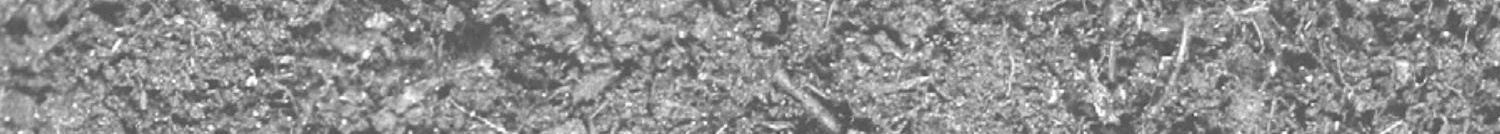
7.

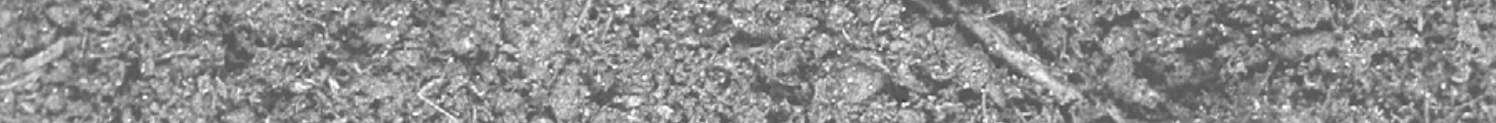

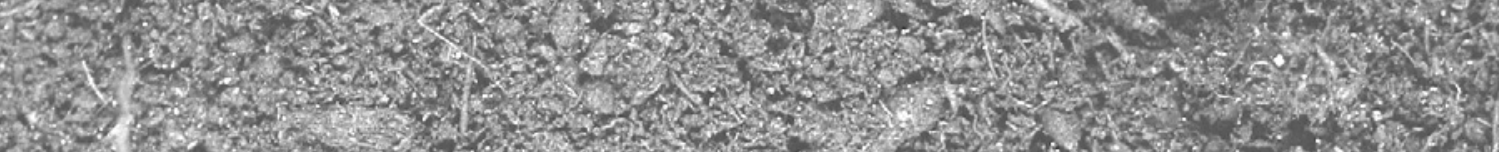

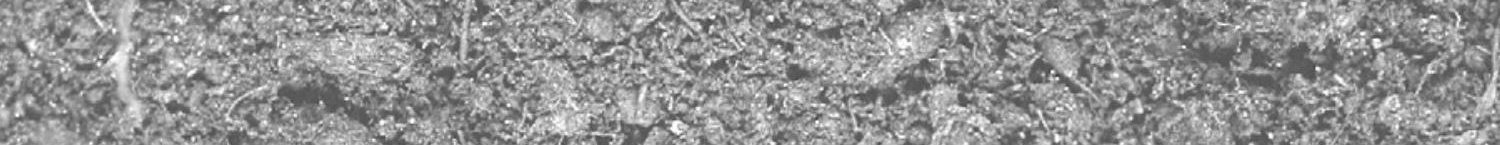

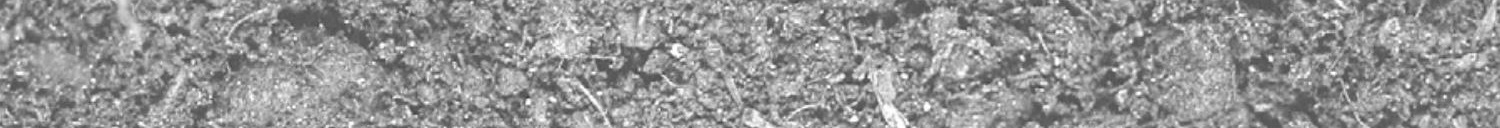
2.6. s.

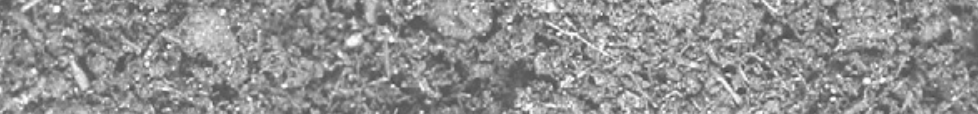

.

\section{(2)}

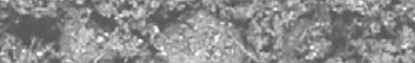
2,300

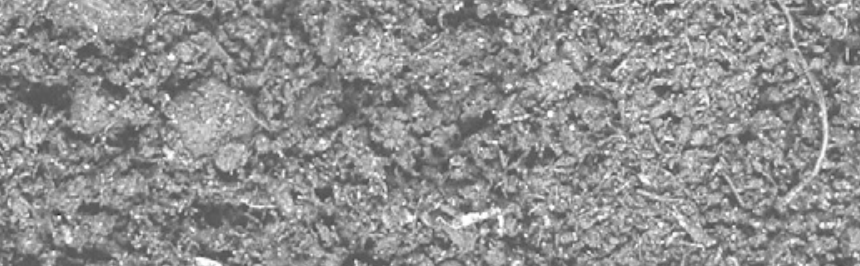
3.

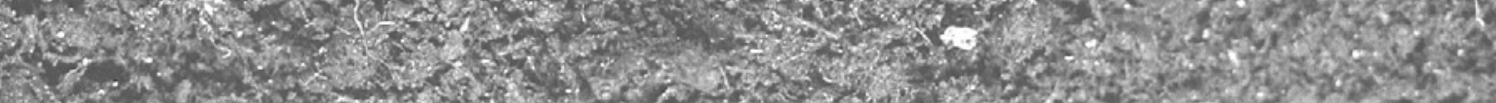

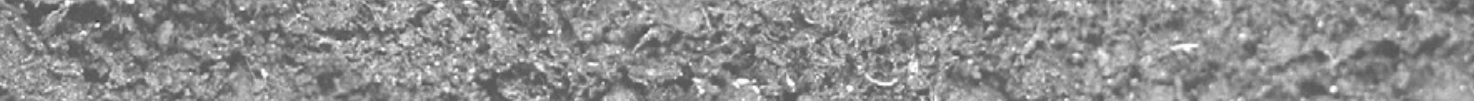
(1)

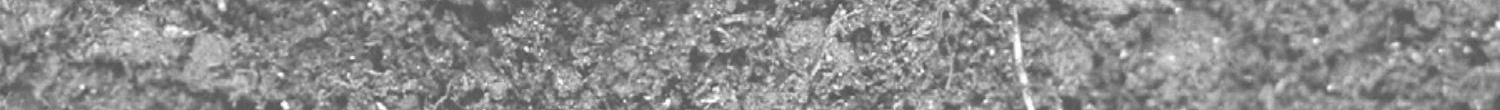
15.

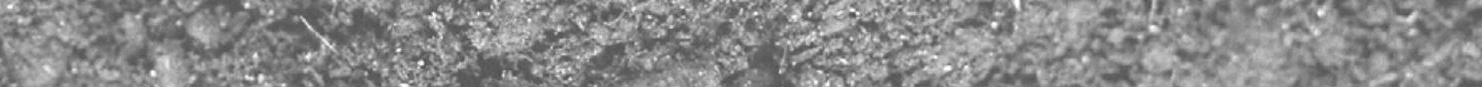

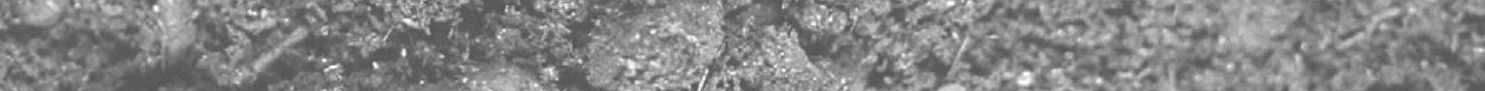



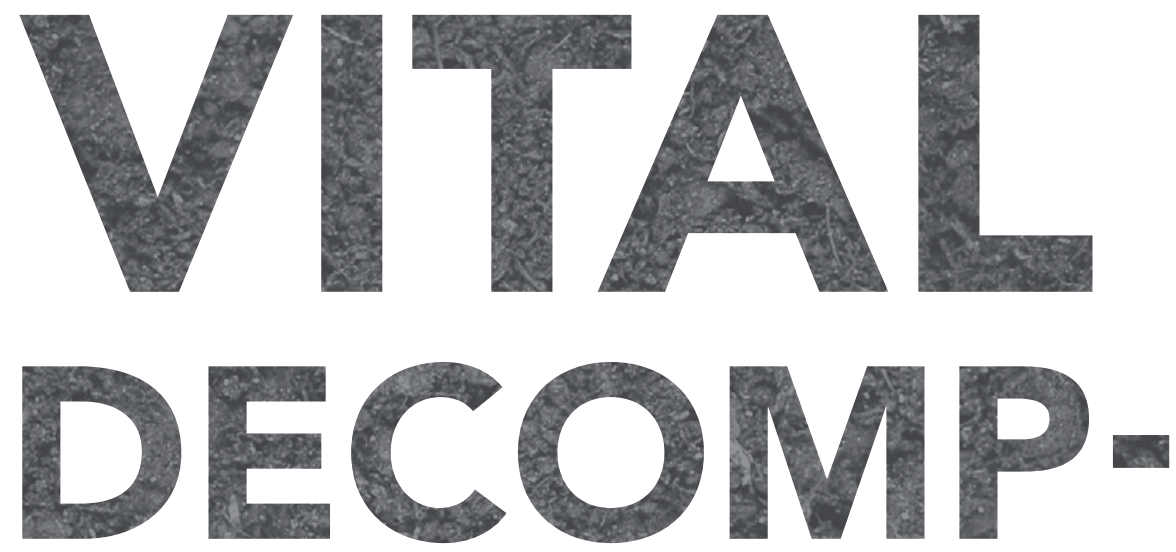

\section{SOIL PRACTITIONERS + LIFE POLITICS}
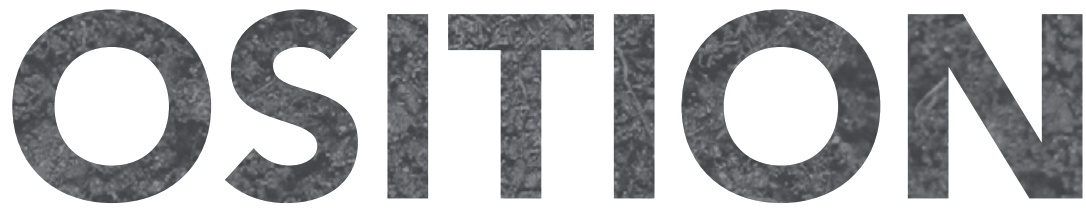

Kristina M. Lyons

Duke University Press Durham and London 2020 
(C) 2020 Duke University Press

All rights reserved

Printed in the United States of America on acid-free paper $\infty$

Designed by Drew Sisk.

Typeset in Minion Pro, Avenir, and Canela Text

by Copperline Book Services.

Library of Congress Cataloging-in-Publication Data

Names: Lyons, Kristina M. (Kristina Marie), [date] author.

Title: Vital decomposition : soil practitioners and life politics /

Kristina M. Lyons.

Description: Durham : Duke University Press, 2020. | Includes

bibliographical references and index.

Identifiers: LCCN 2019032478 (print) | LCCN 2019032479 (ebook)

ISBN 9781478007692 (hardcover)

ISBN 9781478008163 (paperback)

ISBN 9781478009207 (ebook)

Subjects: LCSH: Soil degradation_Colombia-Putumayo (Department) |

Environmental degradation-Colombia-Putumayo (Department) | Nature-

Effect of human beings on-Colombia-Putumayo (Department) | Putumayo

(Colombia : Department)-Environmental conditions.

Classification: LCC s625.C7 L96 2020 (print) | LCC s625.C7 (ebook) |

DDC 631.4/520986163-dc23

LC record available at https://lccn.loc.gov/2019032478

LC ebook record available at https://lccn.loc.gov/2019032479

Cover art and frontispiece: Soil @ Image Source.

Courtesy Getty Images/Image Source. 
Para mi gran familia andinoamazónica,

seguimos soñando despiertxs, caminando juntxs y tejiendo vida.

For teaching me how to live as more than one and less than two. 


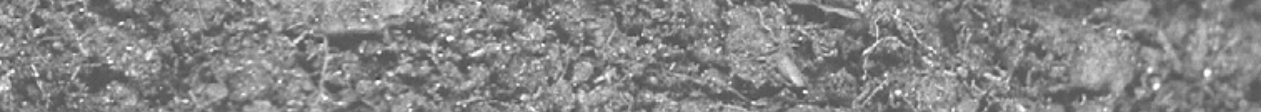

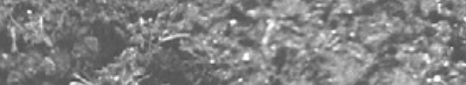

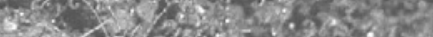

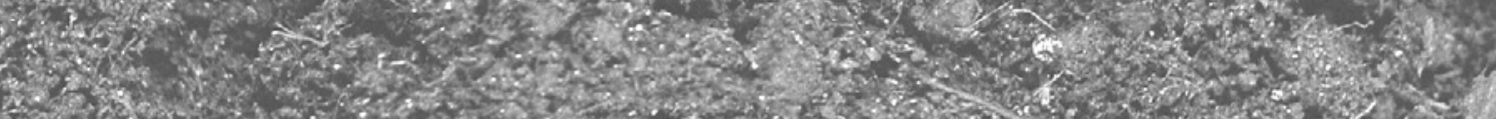

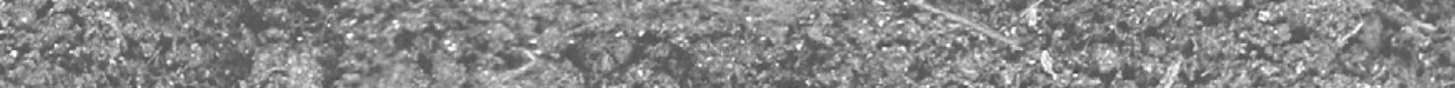

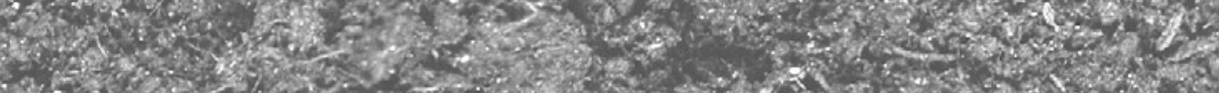

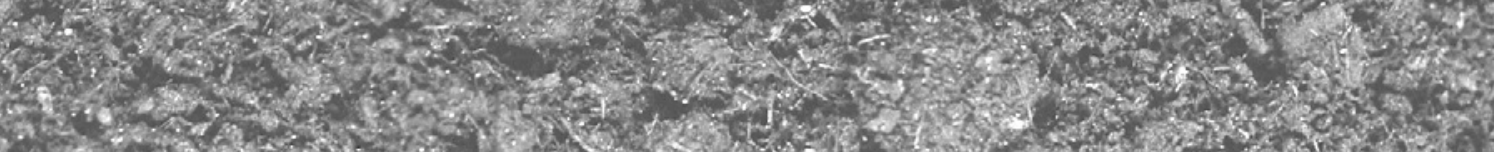

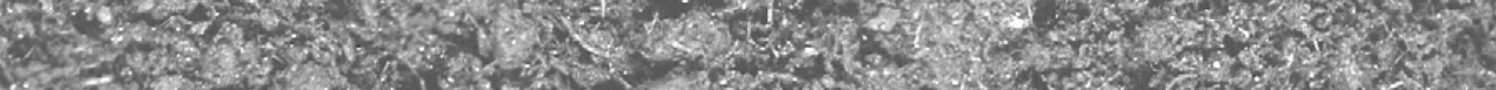

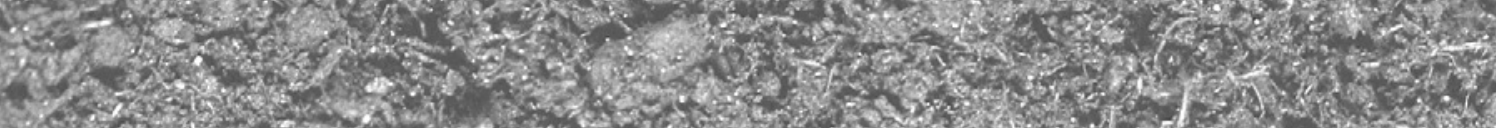

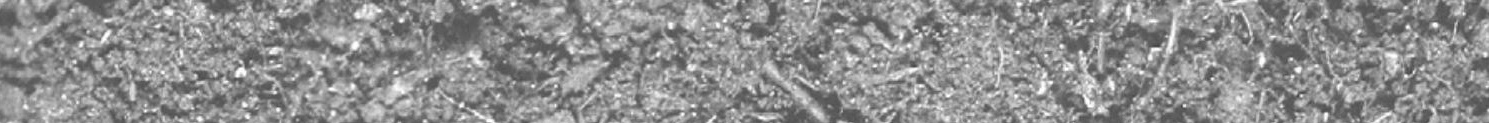

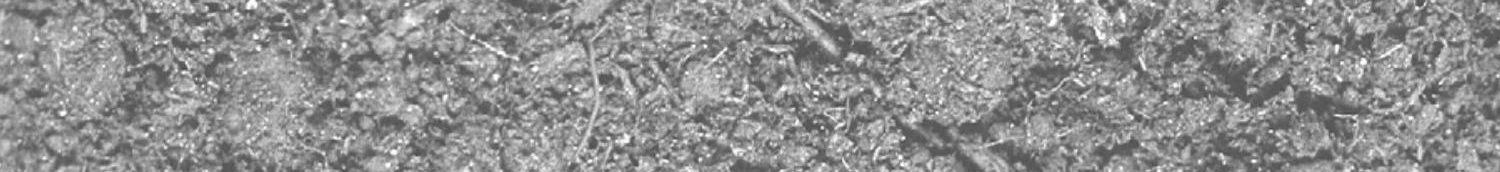
6.5.

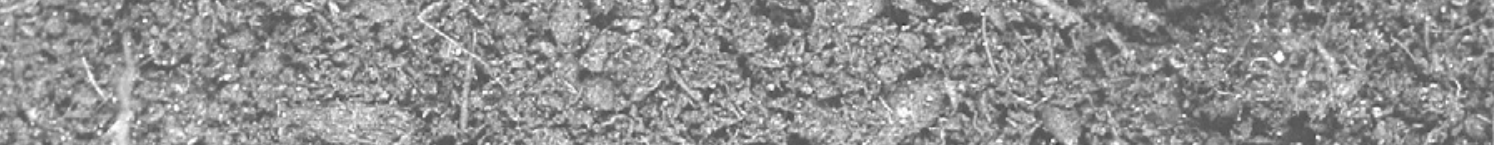

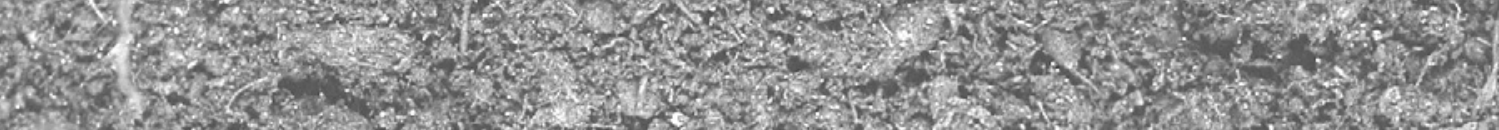

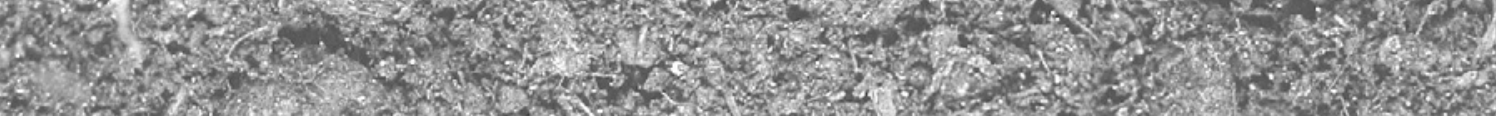

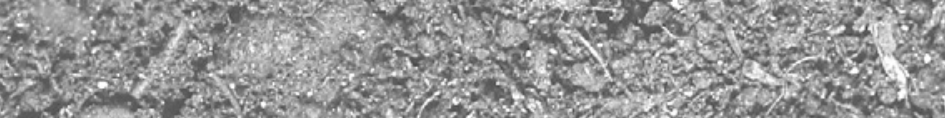

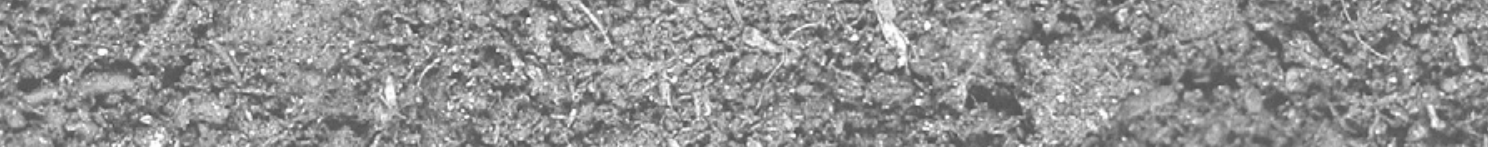
1.5.

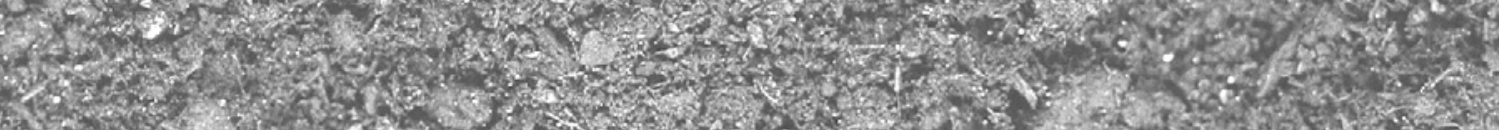

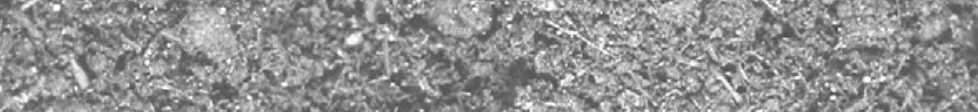

Sofs

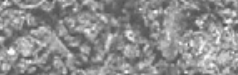

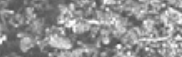

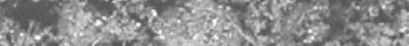

.

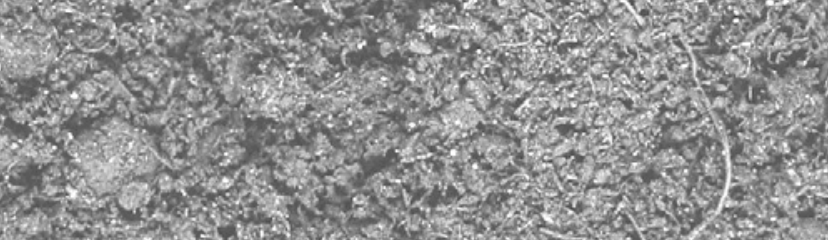
16.

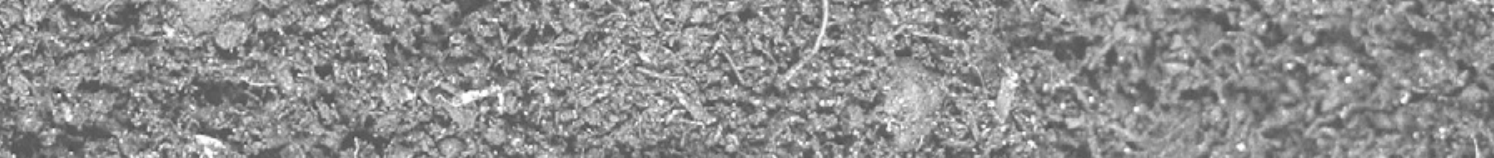

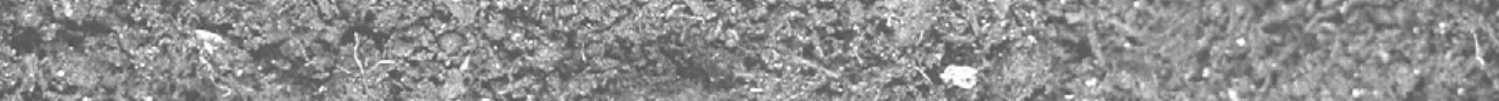

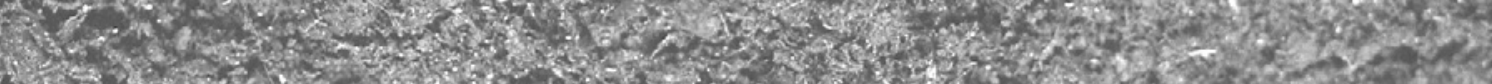

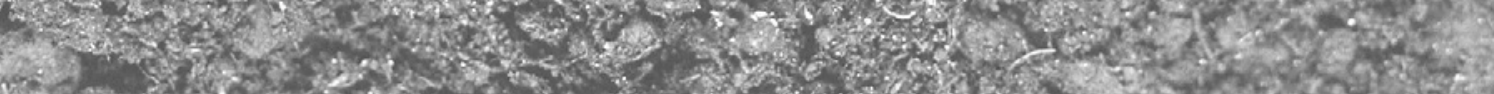
W.

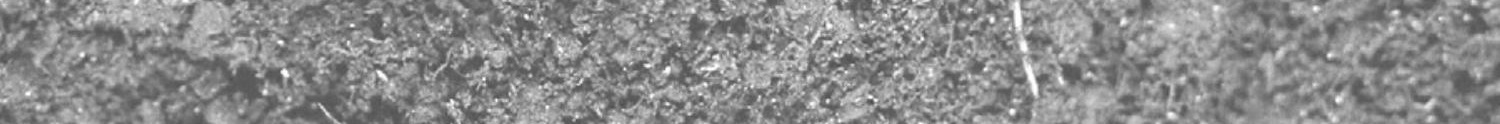

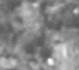

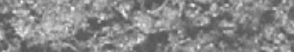

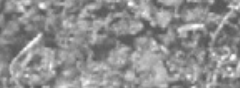
(3) 